\title{
A review of nasal polyposis
}

\author{
Jonathan Ray Newton \\ Kim Wong Ah-See \\ Department of Otolaryngology - \\ Head and Neck Surgery, Aberdeen \\ Royal Infirmary, Aberdeen, Scotland, \\ UK
}

\begin{abstract}
Nasal polyps are common, affecting up to four percent of the population. Their etiology remains unclear, but they are known to have associations with allergy, asthma, infection, cystic fibrosis, and aspirin sensitivity. They present with nasal obstruction, anosmia, rhinorrhoea, post nasal drip, and less commonly facial pain. Clinical examination reveals single or multiple grey polypoid masses in the nasal cavity. Computerized tomography allows evaluation of the extent of the disease and is essential if surgical treatment is to be considered. Management of polyposis involves a combination of medical therapy and surgery. There is good evidence for the use of corticosteroids (systemic and topical) both as primary treatment and as postoperative prophylaxis against recurrence. Surgical treatment has been refined significantly over the past twenty years with the advent of endoscopic sinus surgery and, in general, is reserved for cases refractory to medical treatment. Recurrence of the polyposis is common with severe disease recurring in up to ten percent of patients.
\end{abstract}

Keywords: nasal polyps, disease management, surgical procedures

\section{Introduction}

Nasal polyps (NP) are benign lesions arising from the mucosa of the nasal sinuses (commonly at the outflow tract of one or more of the sinuses) or from the mucosa of the nasal cavity. Having an uncertain etiology and a tendency to recur, they represent a challenging diagnosis for the physician to treat. Management of NP forms a large part of the workload for the otolaryngologist, especially for those with an interest in rhinology.

In addition, it is important for the respiratory physician to be aware of aspects of the treatment of NP which can have a significant impact on chronic obstructive pulmonary disease, in particular asthma.

This paper aims to summarize current trends in all aspects of management of NP.

\section{Search strategy and sources}

We searched MEDLINE ${ }^{\circledR}$ for papers (1977-2007) using "nasal polyposis", "polyps", "diagnosis", and "management" as keywords. We also searched the Cochrane database of systematic reviews using the keywords "nasal polyposis" and "polyps". In addition, we used a personal archive of references relating to our clinical experience.

\section{Etiology of nasal polyposis}

The etiology of NP is unknown. Some theories consider polyps a consequence of conditions which cause chronic inflammation in the nose and nasal sinuses characterized by stromal edema and variable cellular infiltrate (Bateman et al 2003). While many aspects have been documented to support this theory, the initiating cause remains unknown and may be different in many cases.

Historically it has been assumed that allergy predisposed to NP because the symptoms of watery rhinorrhea and mucosal swelling were present in both diseases along with an abundance of eosinophils in the nasal secretions. However, epidemiological
Correspondence: Jonathan R Newton Department of Otolaryngology - Hea and Neck Surgery, Aberdeen Royal 2ZN

Email jnewton59@hotmail.com 
studies provide little evidence to support this relationship with NP found in only $1 \%-2 \%$ of patients with positive skin prick tests (Settipane et al 1977). In addition, studies have shown that NP are no more common in atopic individuals (Jamal et al 1987). Studies have however shown that total and specific $\operatorname{IgE}$ as well as other allergic-type histologic features of polyps are unrelated to positive skin prick tests but did correlate with the levels of eosinophils (Bachert et al 2001). It therefore remains possible that the local allergic mechanisms in the absence of systemic features could play a role in the pathogenesis of polyps.

Many studies have focussed on eosinophilic mediators in NP tissue and demonstrated that different cell types generate these mediators. Interleukine-5 (IL-5) has found to be significantly raised in NP compared with healthy controls and the concentration of IL-5 was independent of the atopic status of the patient (Bachert et al 2001). The key role of IL-5 was supported by the finding that treatment of eosinophil-infiltrated polyp tissue with neutralizing anti-IL-5 monoclonal antibody resulted in eosinophil apoptosis (Simon et al 1997). The regulation of the IL-5 receptor has also been investigated with down regulation being found to occur in NP, especially in association with asthma (Gaevert et al 2003).

An association between polyposis and fungal cultures has been established for many years (Safirstein et al 1976). Further reports linked this finding with allergic bronchopulmonary aspergillosis (Millar et al 1981). This recognition led to the term 'allergic fungal sinusitis' which is diagnosed by the presence of a positive RAS test to fungus, NP, computerized tomography (CT) findings of hyperdense material in the sinus cavity, allergic mucus with histological evidence of eosinophilic preponderance, and identification of fungus in sinus mucus (Bent et al 1994; Ponikau et al 1999). This comes about because of a type 3 hypersensitivity reaction leading to repeated mucosal edema, antigen representation and resultant NP (Marple et al 2001). The precise nature of fungi in the pathogenesis of NP remains unsolved but further research will help clarify this in the future.

There is some evidence for a genetic element to NP. A link has been demonstrated recently between HLA-A74 and NP (Luxenburger et al 2000), but the current knowledge in this area remains very limited.

Medical conditions commonly associated with polyps include asthma, bronchiectasis, and cystic fibrosis (Settipane et al 1996). There is a well recognized subgroup of patients with Samnter's Triad comprising polyposis, asthma, and aspirin hypersensitivity which makes up almost $10 \%$ of cases of NP.

\section{Prevalence}

In the general population, the prevalence of NP is considered to be around 4\% (Hedman et al 1999). In cadaveric studies, this prevalence has been shown to be as high as $40 \%$ (Laren et al 1994). They predominantly affect adults and usually present in patients older than 20. They are uncommon in children under 10 and may be the presenting feature of cystic fibrosis. There is at least a 2:1 male to female preponderance. Up to a third of NP patients have asthma, whereas polyps are only found in 7\% of asthmatics (Settipane et al 1996).

\section{Clinical features}

The main presenting symptom of NP is nasal obstruction which is constant but can vary depending on the site and size of the polyps. Sufferers will also frequently complain of watery rhinorrhea and postnasal drip. Anosmia or hyposmia with an ensuing alteration in taste are also characteristic symptoms of NP (Drake-Lee et al 1997).

Anterior and posterior rhinoscopy reveals single or multiple pale, grey polypoid masses arising most frequently from the middle meatus and prolapsing into the nasal cavity (Figure 1). They consist of loose connective tissue, edema, inflammatory cells, and some capillaries and glands. They are covered with different types of epithelium, most commonly pseudostratified respiratory epithelium with goblet cells and ciliated cells. Studies have shown that eosinophils are the most common inflammatory cells in NP. This leads to a large proportion of IL-5 due to prolonged eosinophil survival and this is one of the important features in differentiating NP from rhinosinusitis at a histo-chemical level (Bachert et al 1997). NP are almost invariably bilateral and when unilateral

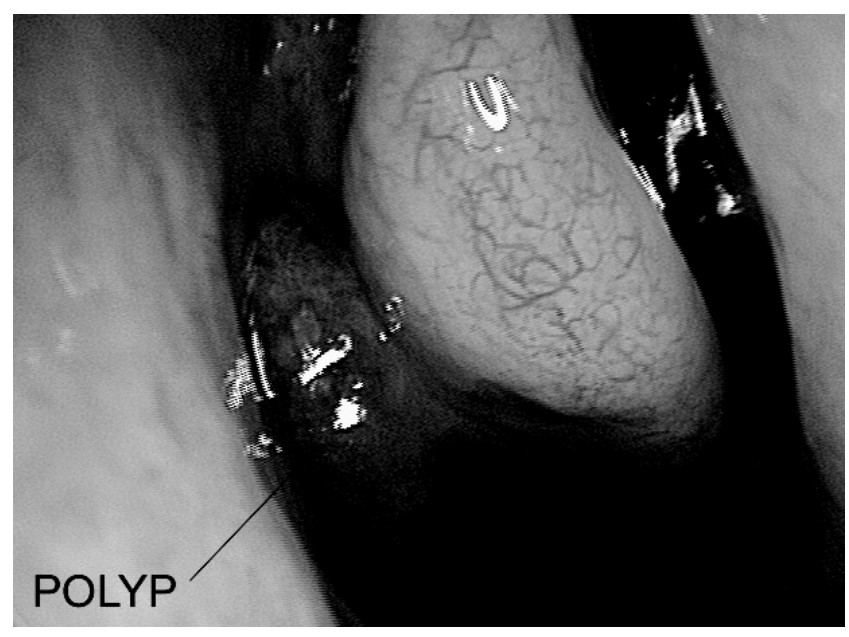

Figure I Typical appearance of nasal polyposis in right middle meatus. 
require histological examination to exclude malignancy or other pathology such as inverted papilloma (Drake-Lee et al 2004). They are insensitive to palpation and rarely bleed.

The histological appearance of NP is characterized by ciliated columnar epithelium, thickening of the basement membrane, a loose avascular edematous stroma and an infiltrate of plasma cells and eosinophils. Eosinophils are found in $85 \%$ of NP with the remaining cells being predominantly neutrophils (Bachert et al 2003).

\section{Investigations}

Plain X-rays are insensitive and of no value in the diagnosis of NP but they may show opacification of the affected sinuses (Iinuma et al 1994). A CT scan will show the extent of NP and anatomical variations and is essential if surgical treatment is to be implemented (Figure 2). It should not be regarded as the primary step in the diagnosis of the condition, except where there are unilateral signs and symptoms or other sinister features, but rather corroborates history and endoscopic findings after failure of medical therapy.

A range of staging systems for $\mathrm{CT}$ scanning have been described, the most commonly used being the Lund-Mackay system (Lund et al 1993). This system relies on a score of 0-2 dependent on the absence, partial, or complete opacification of each sinus system and of the vital ostiomeatal complex deriving a maximum score of 12 per side. This has been validated but the correlation between the CT score and symptoms has been shown to be poor and is not a good indicator of outcome (Browne et al 2006).

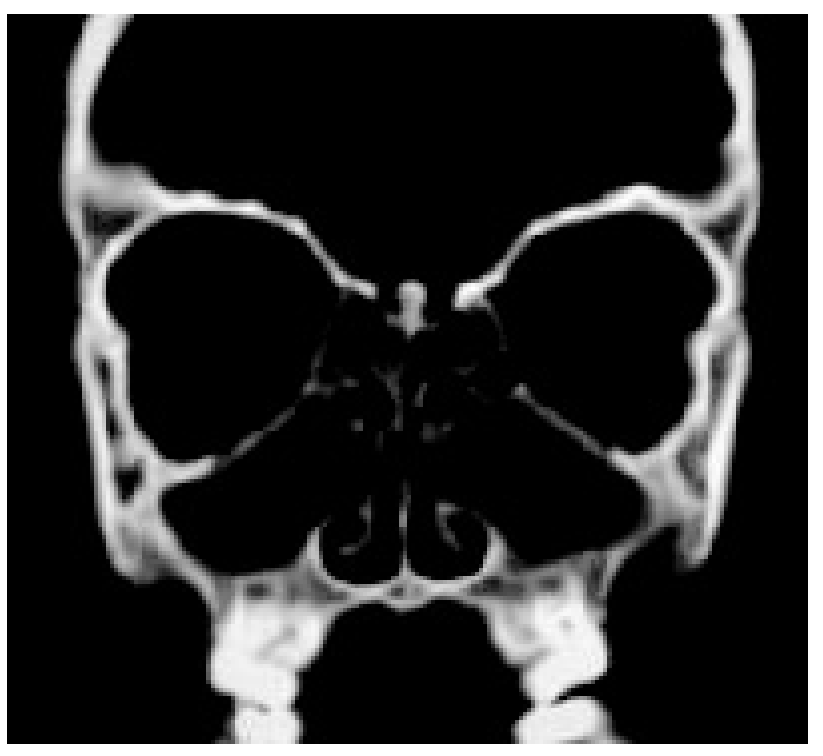

Figure 2 Coronal CT showing pan-opacification of the sinuses.
In unilateral cases of NP, an magnetic resonance imaging scan may aid diagnosis, particularly for investigations of more serious conditions such as neoplasia.

\section{Treatment of NP}

Therapy for NP involves a combination of observation, medical, and surgical treatments depending on individual case assessment. In general, patients are treated medically in the primary care setting before consideration of surgical procedures by an otolaryngologist. The aims of treatment are to eliminate or significantly reduce the size of the NP resulting in relief of nasal obstruction, improvement in sinus drainage, restoration of olfaction and taste. Treatment of any accompanying rhinitic symptoms may also be required (Mygind et al 1999). With both treatments, recurrences are common, particularly in patients with asthma who are twice as likely to develop recurrence compared with nonasthmatics (Dinis et al 1997).

\section{Medical treatment}

The advent of topically administered corticosteroids has improved the treatment of upper (NP and rhinitis) and lower (asthma, chronic obstructive airways disease) airways disease (Fokkens et al 2007). Their clinical efficacy is achieved by a combination of anti inflammatory effects along with their ability to reduce airway eosinophillic infiltration by preventing their increased viability and activation (Burgel et al 2004). Both topical and systemic glucocorticoids may affect the eosinophil function by both directly reducing eosinophil viability and function or indirectly reducing the secretion of chemotactic cytokines by nasal mucosa and polyp epithelial cells (Roca-Ferrer et al 1997). Corticosteroids form the mainstay of conservative therapy in NP as both a primary treatment and to prevent recurrence. In the absence of other warning signs such as pain, bleeding, or unilateral polyps, treatment can be largely conducted in the primary care setting. Corticosteroids should be used with caution in 'at-risk groups' particularly patients with diabetes, uncontrolled hypertension, and peptic ulcer disease.

Treatment should commence with topical nasal steroids (Badia et al 2001) along with aggressive treatment of any underlying cause or comorbid allergy. Topical nasal steroids are delivered by drops or sprays. Nasal drops deliver a higher dose of medication to the middle meatus and the lying, head-back position has been shown to be both comfortable and effective (Kayarker et al 2002).Topical steroids have been investigated extensively. Stjarne and colleagues (2006) compared in 298 subjects with moderate NP mometasone 
furoate nasal spray (MFNS) with placebo for 16 weeks. They found a significant decrease in nasal congestion, polyp size, and improved quality of life. Lund and colleagues (1998) compared fluticasone propionate (FP) with placebo in 46 patients for 12 weeks in a randomized controlled trial. Polyp score and acoustic rhinometry improved significantly in the NP group. Steroids have been shown to improve nasal breathing, improve symptoms of rhinitis, and reduce the size of NP along with the rate of recurrence (Patiar et al 2007). Despite this proven symptomatic benefit, there remains debate however about the efficacy of steroids in reduction of the proportion of patients requiring surgery (Browning et al 2007). One trial has certainly showed a reduced rate of surgical treatment, but it is acknowledged further research is required in this area (Albertien et al 2005).

Systemic steroids are reserved for advanced or refractory cases particularly when allergy is present. This form of treatment is used for relatively rapid short-term improvement due to the risk of adverse effects (Mygind et al 1996). This treatment is very effective. Van Camp and colleagues (1993) performed an open study giving $60 \mathrm{mg}$ of prednisolone to 25 patients with severe polyposis for four days then for each of the following twelve days reduced the dose by $5 \mathrm{mg}$ daily; symptoms were improved especially obstruction and anosmia and CT findings resolved in $52 \%$ of cases.

Hissaria and colleagues (2006) compared $50 \mathrm{mg}$ prednisolone daily for 14 days with placebo. A significant difference was found in nasal symptoms and endoscopic findings. This sometimes dramatic improvement in anatomical appearance and symptom relief has been termed a 'medical polypectomy'. There is a paucity of evidence comparing systemic steroids with topical treatments. There are no randomized controlled trials in the literature comparing outcomes of systemic steroids and surgery (Bateman et al 2003). The adverse effects of short-term steroid use include glucose intolerance, hypertension, adrenal suppression, gastro-intestinal bleeding, and altered mental state. Once symptoms have resolved, it is important to maintain improvement with long-term intranasal steroids in the form of aqueous nasal spray.

In all patients the addition of simple saline nasal douching to help cleanse the nose prior to topical medications is beneficial (Fokkens et al 2007). These irrigations have been shown to improve nasal mucocilliary clearance measured by the saccharine test in both NP and healthy volunteers in an American study (Talbot et al 1997). These are typically available over the counter in most pharmacies.

Antibiotics are frequently used in chronic rhinsinusitis (Fokkens et al 2007) as well as in acute sinusitis but they are not effective in medical management of uncomplicated NP (Bateman et al 2003; Fokkens et al 2007). Mucolytics can be used as adjuncts to antibiotics in acute sinusitis to reduce viscosity of sinus secretion but no clinical trials have tested their effects in NP. Antihistamines can have significant reduction in symptoms in simple NP. One study showed reduction in sneezing, rhinorrhea, and obstruction compared with placebo, but there was no reduction in polyp size at 3 months (Haye et al 1998).

Other medical therapies have been used for treatment of NP. Leukotriene receptor antagonists have recently been shown to be effective (Kieff et al 2005), but larger scale trials are required to prove their efficacy. Topical capsaicin has also been shown to be effective, but side-effects including burning of the nasal mucosa limit its acceptability to patients (Baudoin et al 2000). There is little evidence to advocate the usage of other treatments including frusemide and interferonalpha2a and neither of these is available in routine medical practice (Bateman et al 2003).

Allergic fungal rhinosinusitis is treated by both topical and systemic antimycotics as an adjunct to sinus surgery. Surgery is considered the first-line therapy particularly for invasive fungal rhinosinusitis (Schubert et al 2000). This management is however based on a small series of patients and case reports and should be considered as level 4 evidence.

\section{Surgical treatment}

Surgical therapy is reserved for cases refractory to medical treatment. No single surgical technique has proved to be entirely curative and patients often undergo repeat procedures despite also receiving long-term medical therapy. Recurrence is common with severe disease recurring in around 5\%-10\% patients (Fokkens et al 2007).

Surgical techniques have been significantly refined over the past 20 years with the advent of endoscopic sinus surgery (ESS) (Kennedy et al 2001). With a better understanding of the anatomy of the osteomeatal complex (Figure 3 ) and pathways of mucocilliary clearance, ESS is now the mainstay of treatment for NP. In the National Health Service Research and Development Health Technology Assessment Programme Evaluation, polyp recurrence was $28 \%$ following endoscopic sinus surgery compared with 35\% following intranasal polypectomy (Dalziel et al 2003).

Hopkins and colleagues analyzed 1848 patients with nasal polyps who participated in the National Comparative Audit of Surgery for Nasal polyposis and Rhinosinusitis. The postoperative symptom scores did not differ 


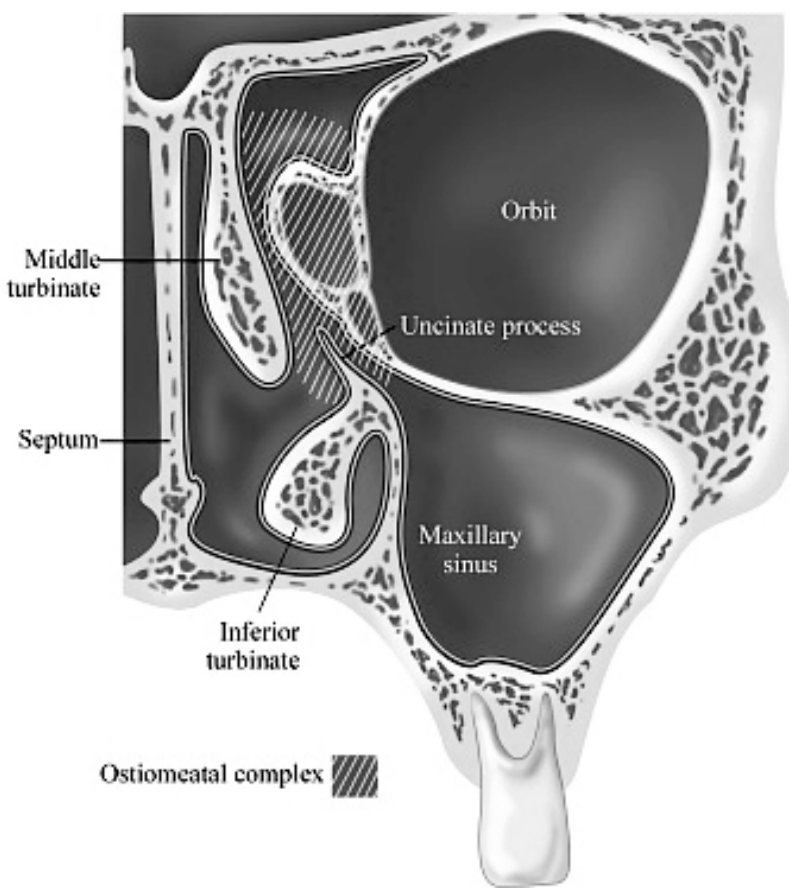

Figure 3 Anatomy of the osteomeatal complex.

significantly after 12 and 36 months but revision surgery was carried out more frequently in the polypectomy only group in the first twelve months after surgery (Hopkins et al 2006).

Despite this, many surgeons continue to perform simple avulsion polypectomy with good results (Larsen et al 1997). ESS involves restoring sinus drainage by careful removal of NP or other soft tissue obstructing the natural sinus ostia (Messerklinger et al 1987). This can be done by traditional snare polypectomy, cold steel instruments, or the increasingly more common technique of micro-debridement, which involves a rotating blade in combination with suction and irrigation. There is some research available that radical endoscopic sinus procedures involving complete fronto-sphenoidectomies lead to greater perceived benefits (Jacobsen et al 2000). More extensive surgery can lead to increased risk of operative complications but to date no comparative study exists between radical and limited surgery.

There is little doubt that ESS offers better visualization and scope for precision surgery. The micro-debrider (Figure 4) in particular enables accurate removal of NP whilst preserving normal anatomical structures such as the turbinates. Serious complications of ESS are rare but the patient must be counseled preoperatively about the potential risks such as loss of vision, damage to the internal carotid artery, and cerebrospinal fluid leakage after inadvertent trauma to the skull base (Stammberger et al 1999).

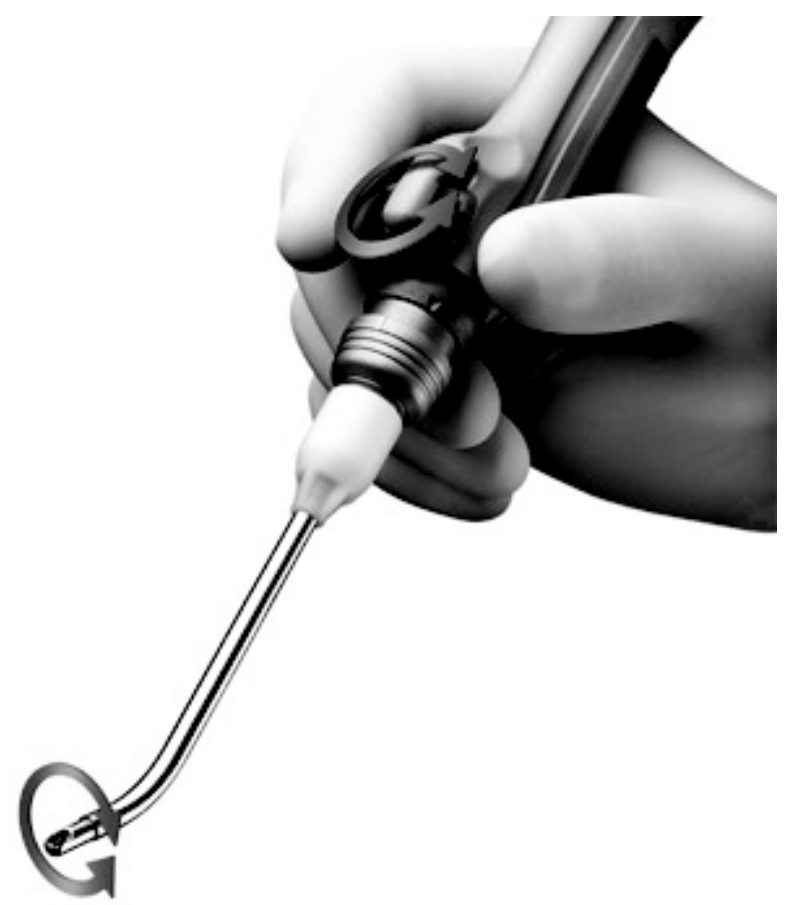

Figure 4 Micro-debrider used in endoscopic sinus surgery.

It is important postoperatively to regularly douche the nasal cavity with saline to prevent crusting and adhesions. Topical intranasal steroids are also a routine part of aftersurgery care to prevent recurrence. Rowe Jones and colleagues (2005) studied a group of 109 patients prospectively for 5 years postoperatively. Seventy two patients attended the 5 year follow-up visit. All patients were entered in a randomized double blinded controlled study of fluticasone propionate aqueous spray. Symptom scores were significantly better in the treatment group at 5 years (Rowe Jones et al 2005).

\section{References}

Albertien AC, Aukema MD, Mulder PDH. 2005. Treatment of nasal polyposis and chronic sinusitis with fluticasone propionate nasal drops reduces the need for sinus surgery. J Allergy Clin Immunol, 115:1017-23.

Bachert C, Gevaert P, Holappels G, et al. 2001. Total and specific IgE in nasal polyps is related to local eosinophilic inflammation. $J$ Allergy Clin Immunol, 107:607-14.

Bachert C, Hormann K, Mosges R. 2003. An update on the diagnosis and treatment of sinusitis and nasal polyposis. Allergy, 58:176-91.

Bachert C, Wagenmann M, Hauser U, et al. 1997. IL-5 synthesis is upregulated in human nasal polyp tissue. J Allergy Clin Immunol, 99:837-42.

Badia L, Lund V. 2001. Topical corticosteroids in nasal polyposis. Drugs, 61:573-8.

Bateman ND, Fahy C, Woolford TJ. 2003. Nasal polyps: still more questions than answers. $J$ Laryngol Otol, 117:1-9.

Baudoin T, Kalogjera L, Hat JI. 2000. Capsaicin significantly reduces sinonasal polyps. Acta Otolaryngol, 120:307-11.

Bent JP, Kuhn FA. 1994. Diagnostic of allergic fungal sinusitis. Otolaryngol Head Neck Surg, 111:580-8. 
Browne JP, Hopkins C, Slack R, et al. 2006. Health related quality of life after polypectomy with and without additional surgery. Laryngoscope, 116:297-302.

Browning GG. 2007. Management of nasal polyps with steroids; the current literature. Clin Otolaryngol, 32:195.

Burgel PR, Cardell LO, Ueki IF, et al. 2004. Intranasal steroids decrease eosinophils but not mucous expression in nasal polyps. Eur Resp $J$, 24:594-600

Dalziel K, Stein K, Round A, et al. 2003. Systematic review of endoscopic sinus surgery for nasal polyps. Health Technol Assess, 7:1-159.

Dinis PB, Gomes A. 1997. Sinusitis and asthma; how do they interrelate in sinus surgery? Am J Rhinol, 11:421-8.

Drake-Lee AB. 1997. Nasal polyps. In: KerrAG, MackayAS, BullTR eds. Scott-Brown's Otolaryngology. 6th Edition. Vol. 4. Rhinology, Oxford: Butterworth-Heinneman, 4/10/1-16.

Drake-Lee AB. 2004. Nasal polyps. Hospital Med, 65:264-7.

Fokkens W, Lund V, Mullol J; European Position Paper on Rhinosinusitis and Nasal Polyps Group. 2007. EP3OS 2007: European position paper on rhinosinusitis and nasal polyps 2007. A summary for otorhinolaryngologists. Rhinology, 45:97-101.

Gaevert P, Bachert C, Novo CP, et al. 2003. Enhanced soluble Interleukin-5 receptor alpha expression in nasal polyposis. Allergy, 58:371-9.

Haye R, Aaneson JP, Burtin B, et al. 1998. The effect of cetirizine on symptoms and signs of nasal polyposis. J Laryngol Otol, 112:1042-6.

Hedman J, Kaprio J, Poussa T, et al. 1999. Prevalence of asthma, aspirin intolerance, nasal polyposis and chronic obstructive pulmonary disease in a population-based study. Int J Epidemiol, 28:717-22.

Hissaria P, Smith W, Wormald PJ, et al. 2006. Short course of systemic corticosteroids in sinonasal polyposis: A double-blinded, randomized, placebo-controlled trial with evaluation of outcome measures. J Allergy Clin Immunol, 118:128-33.

Hopkins C, Browne JP, Slack R, et al. 2006. The national comparative audit of surgery for nasal polyps and chronic rhinosinusitis. Clin Otolaryngol, 31:390.

Iinuma T, Hirota Y, Kase Y. 1994. Radio-opacity of the paranasal sinuses. Conventional views and CT. Rhinology, 32:134-6.

Jacobsen J, Svendstrup F. 2000. Functional endoscopic sinus surgery in chronic sinusitis- a series of 237 consecutively operated patients. Acta Otolaryngol, 543:158-61.

Jamal A, Maran AGD. 1987. Atopy and nasal polyposis. J Laryngol Otol, 101:355-8.

Kayarker R, Clifton NJ, Woolford TJ. 2002. An evaluation of the best head position for instillation of nasal steroid drops. Clin Otolaryngol, 27:18-21.

Kennedy DW, Bolger WE, Zinerich SJ. 2001. Diseases of the sinuses; diagnosis and endoscopic management. Hamilton and London: Decker.

Kieff DA, Busaba NY. 2005. Efficacy of montelukast in the treatment of nasal polyposis. Ann Otol Rhinol Laryngol, 114:941-5.

Laren PL, Tos M. 1994. Anatomic site of origin of nasal polyps: endoscopic nasal and paranasal sinus surgery as a screening method for nasal polyps in autopsy material. Rhinology, 33:185-8.
Larsen K, Tos M. 1997. A long-term follow-up study of nasal polyp patients after simple polypectomies. Eur Arch Otorhinolaryngol, 1:85-8.

Lund V, Mackay IS. 1993. Staging in chronic rhinosinusitis. Rhinology, 31:183-4.

Lund VJ, Fllod J, Sykes A, et al. 1998. Effect of fluticasone in severe polyposis. Arch Otolaryngol Head Neck Surg, 124:513-18.

Luxenburger W, Posch G, Berghold A, et al. 2000. HLA patterns in patients with nasal polyposis. Eur Arch Otorhinolaryngol, 257:137-9.

Marple BF. 2001. Allergic fungal rhinosinusitis: current management and theories. Laryngoscope, 111:1006-17.

Messerklinger W. 1987. Role of the lateral nasal wall in the pathogenesis, diagnosis and therapy of recurrent and chronic sinusitis. Laryngol Rhinol Otol, 66:293-9.

Millar AW, Johnson A, Lamb D. 1981. Allergic aspergillosis of the maxillary sinuses. Thorax, 36:710.

Mygind N. 1999. Advances in medical treatment of nasal polyps. Allergy, $54: 12-16$.

Mygind N, Lildholdt T. 1996. Nasal polyps treatment: medical management. Allergy Asthma Proc, 17:275-82.

Patiar S, Reece P. 2007. Oral steroids for nasal polyps. Review. The Cochrane Collaboration. Published by John Wiley and Sons, Ltd.

Ponikau JU, Sherris DA, Kern EB. 1999. The diagnosis and incidence of allergic fungal sinusitis. Mayo Clin Proc, 74:877-84.

Roca-Ferrer J, Mullol J, Xaubet A. 1997. Effect of topical anti-inflammatory drugs on epithelial cell-induced eosinophil survival and GM-CSF secretion. Eur Respir J, 10:1489-95.

Rowe Jones JM, Medcalf M, Durham SR, et al. 2005. Functional endoscopic sinus surgery: 5 year follow up and results of a prospective randomised double-blind placebo controlled trial of post-operative fluticasone propionate nasal spray. Rhinology, 43:2-10.

Safirstein BH. 1976. Allergic bronchopulmonary aspergillosis with obstruction of the upper respiratory tract. Chest, 70:788-90.

Schubert MS. 2000. Medical treatment of allergic fungal sinusitis. Ann Allergy Asthma Immunol, 85:90-7.

Settipane GA. 1996. Epidemiology of nasal polyps. Allergy Asthma Proc, 17:231-6.

Settipane GA, Chafee FH. 1977. Nasal polyps in asthma and rhinitis. A review of 6037 patients. J Allergy Clin Immunol, 59:17-21.

Simon HU, Yousefi S, Schranz C. 1997. Direct demonstration of delayed eosinophilic apoptosis as a mechanism causing tissue eosinophilia. J Immunol, 158:3902-8.

Stammberger H. 1999. Surgical treatment of nasal polyps: past, present, and future. Allergy, 54:7-11.

Stjarne P, Mosges R, Jorissen M, et al. 2006 Randomized controlled trial of mometasone furoate nasal spray for the treatment of nasal polyposis. Arch Otolaryngol Head Neck Surg, 132:179-85.

Talbot AR, Herr TM, Parsons DS. 1997. Mucocilliary clearance and buffered hypertonic saline solution. Laryngoscope, 107:500-3.

Van Camp C, Clement PAR. 1993. Results of oral steroid treatment in nasal polyposis. Rhinology, 32:3-9. 